\title{
Personal Narratives: A Pedagogical Proposal to Stimulate Language Students' Writing
}

\section{Narrativas personales: una propuesta pedagógica para estimular la escritura en estudiantes de idiomas*}

\author{
Fredy Orlando Salamanca González \\ fredyo.salamanca@gmail.com \\ Universidad Pedagógica y Tecnológica de Colombia, Tunja, Colombia
}

In a public university in Tunja (Colombia), undergraduate language students mentioned that writing was important and yet, they kept at a distance from it due to its requirements. The aim of this pedagogical intervention was to find a strategy to encourage students to write and, more importantly, to feel an identity with their texts. For this pedagogical intervention, students were required to write narratives that allowed them to portray their experiences using the target language and to look for the most accurate words and descriptions. From a pedagogical perspective, writing the narratives provided the teacher with the possibility of knowing his students better and to feel an affiliation towards them.

Key words: Life experiences, personal narratives, students' feelings, writing in a second language.

En una universidad pública en Tunja, estudiantes de pregrado de un programa de idiomas mencionaron que saber escribir es importante pero las exigencias escriturales hacen que se alejen de ella. La intención de esta intervención pedagógica fue la de encontrar una estrategia para que los estudiantes escribieran y, además hacer que ellos se identificaran con sus textos. Se implementó el uso de narrativas que permitieran a los estudiantes retratar sus experiencias en el idioma extranjero con palabras y descripciones precisas. Desde el punto de vista pedagógico, las narrativas le facilitaron al docente conocer a sus estudiantes y sentir afinidad hacia ellos.

Palabras clave: escritura en lengua extranjera, experiencias de vida, narrativas personales, sentimientos de los estudiantes.

* Received: July 31, 2014. Accepted: February 2, 2015.

How to cite this article (APA 6th ed.):

Salamanca González, F. O. (2015). Personal narratives: A pedagogical proposal to stimulate language students' writing. HOW, 22(1), 65-79.

This article is licensed under a Creative Commons Attribution-NonCommercial-NoDerivatives 4.0 International License. License Deed can be consulted at http://creativecommons.org/licenses/by-nc-nd/4.0/ . 


\section{Introduction}

This intervention was applied to third semester students in a BA in languages program at a public university in Tunja (Colombia). As part of their academic activities, students are exposed to different subjects related to writing and are therefore expected to write creative and academic texts. Thus, during the languages program students explore their writing skills from different perspectives. Despite the fact that students write many texts, they usually make some mistakes. Apprentices' compositions lack of ideas development, good grammar and proper word choice is not acceptable. As stated by Kim and Kim (2005), "these functional language use problems are worsened because writing teachers tend to focus largely on teaching students grammar, and proper language structure, and typically see students as passive writers" (p. 2).Despite the fact that formal aspects are important in writing, the message that the text can imply is more important as well as the presence of the author along the paper. This pedagogical proposal is therefore intended to empower students to take an active role in their writing, and to have them reflect on the application of grammar, punctuation, coherence, and so on, in their texts. Their voices are important and they can be heard by means of the target language.

Despite BA students being constantly required to write essays, reviews, or stories, they found writing difficult and demanding. For this intervention, after an initial survey was applied, apprentices mentioned that obstacles for writing had to do with grammar, expressions, and word choice. They implied that writing is a process that takes time and that a lot of practice is needed if a person wants to become a writer.

On the other hand, students argued that grammatical knowledge made writing in English a difficult task. They stated that English language rules limited their production and that grammar did not allow them to pay attention to the development of their ideas. Besides, for them it was frustrating to spend time and effort on a paper to get a low score. The previous aspects were vital for students to write the narratives as an option to explore their written production.

There was a common issue that students faced: They stated that they did not know how to start a text. After two sessions, students had many pages written; they wrote in class and in tutorial sessions and the texts were read by their teacher in order for her/him to suggest expressions, grammar, and descriptions. After the implementation, students realized that, on the one hand, grammar was a small feature in writing and that, on the other hand, they were able to achieve very well constructed texts.

Narratives became a positive pedagogical experience. By means of writing, students were able to illustrate their lives and their feelings and to display the way they saw their worlds. From the teachers' perspective, the narratives were relevant for getting to know students. 
Inside a classroom there can be found numerous motivations to study a language, many ideas about life and a lot of experiences that deserve to be told, and it is by means of writing that students' experiences are materialized.

\section{Literature Review}

Narratives have proven to be a valuable resource for language classrooms. Narratives reveal a way to see the world, to feel sensations, and to recall memories. Those personal experiences can be applied to the languages field to explore students' writing skills in English. Narratives are meaningful for students because the texts are connected to their own lives, thus learning the target language combined with students' voices becomes a rich experience. On the one hand, narratives are a space where students have the freedom to tell what they want to and how they want to; on the other, by means of narratives, teachers can know better who their students are.

\section{Narratives}

Narratives are tied to personal events and explained in a particular way. Thus, it is worthwhile to assert that narratives are also specific to each person. As Bamberg and McCabe put it:

With narrative, people strive to configure space and time, deploy cohesive devices, reveal identit[ies] of actors and relatedness of actions across scenes. They create themes, plots, and drama. In doing so, narrators make sense of themselves, social situations, and history (as cited in Riessman, 2003, p. 7).

Narratives imply a reflective exercise of remembering, analyzing, and displaying events on a piece of paper. As a result, the narrators make sense of their own lives according to the situations experienced and according to the people that were involved in those events: "People attempt to create a link to explain events and experiences in their lives. The process of narrating experience is not merely a communication tool, but also one that allows to negotiate and/or make meaning out of it" (Miyahara, 2010, p. 10).

The term narrative is also related to discourse. By means of discourse and reflection, the role that a person has in the society can be evaluated.

[A narrative] is basically ... a discourse or a way of using language to construct stories (Bruner, 1990).This holds various implications: firstly, it indicates that a narrative is a means by which individuals define and recreate themselves through the discursive construction of identity (Martinez-Roldan, 2003);secondly, it suggests that individuals organize their experiences in terms of stories (Burr, 2003).” (Miyahara, 2010, p. 5)

Furthermore, Mistry (as cited in Pavlenko, 2008) argues that narrative "refers to all types of discourse in which event structured material is shared with readers or listeners, including 
fictional stories, personal narratives, accounts and recounts of events (real or imagined)" (p. 311). Similarly, it has been established that narratives follow some parameters. Riessman (2003), for instance, states that a narration has a sequence and contains a plot based on experience; narratives can be organized temporally, spatially, thematically, or episodically.

Despite narratives being written about personal experiences, the texts must accomplish some characteristics. The simple fact of narrating or telling a story cannot be considered as a narrative per se. When a narrative lacks time or setting it is an incomplete or pointless narrative. Narratives should contain six elements:

the abstract (a summary of the subject of the narrative); the orientation (time, place, situation, participants); the complicating action (what actually happened); the evaluation (the meaning and significance of the action); the resolution (what finally happened); and lastly the coda, which returns the perspective to the present. (Labov \& Waletzky as cited in Elliott, 2005, p. 9)

Applying the six previous elements allows the narrator to link the sequence of events and to make sense of their experiences.

Every person's life is a story. Every person lives incidents that are worth to be heard. As narratives can be considered discourses, as a consequence, they carry identities within. Any word or text involves intentions, meanings, and points of view. In that sense, "discourses comprise ways of understanding the world, talking about it and-especially but not limited to-_becoming and/or being' within it" (Castañeda-Peña, 2008, p. 114). Discourses, similar to identity, imply the presence of a point of view in relation to specific issues. Narratives reveal who the writers are, how they perceive the world, and how they coexist within their context.

Narratives can also be considered as an educational research instrument. Narratives "provide researchers with a rich framework through which they can investigate the ways humans experience the world depicted through their stories" (Webster \& Mertova as cited in Rivas Rivas, 2013, p. 189). Education should be centered on students; teachers are guiders and must build a space to allow students to find knowledge by themselves. With narratives, apprentices are able to discover their own way of thinking using the target language. Narratives provide enough information for a researcher to elucidate certain aspects from students, for example, imaginary identities. Students' voices are valuable and every classroom should create a small space in which they can illustrate their thoughts by means of writing. Narratives can help teachers to research with the very same perceptions of the students. Thus, a suitable way to build a text is by asking students to write around their existence.

Narratives can be classified into two categories: fictional narratives and personal narratives. Fictional narratives are stories about unreal events using prompt, pictures, or videos; personal narratives: 
are stories about real, imagined, or possible events that draw on speakers' experiences. They can be elicited in experimental settings through key words, interview questions, or requests to tell particular types of stories, such as earliest memories, stories about holidays or car accidents, or stories about times when the speakers felt a particular emotion. (Pavlenko, 2008, p. 318)

The narratives that were implemented in this intervention were the personal narratives. Personal narratives accounted for experiences, memories, and sensations. For writing the narratives, students were requested to write about their lives and their reflections about what happened around them.

Rodriguez Guanume (2013) used personal narratives to explore students' self-perceptions as learners in a school in Tota (Boyacá, Colombia). By means of narratives, the researcher could establish that teachers had a big influence on teenagers' behaviors, attitudes, and thoughts. According to the researcher, teachers influence students' perceptions and the construction of their selves. On the other hand, the researcher found that despite language limitations students achieved their communicative goals. The narratives were not completely precise in terms of grammar and language accuracy, but the message conveyed was comprehensible for the reader; consequently, a point of view was clearly stated in the texts.

A research study carried out by Guerrero (2011) also exemplifies the usefulness of narratives. The researcher worked with a high school student in Bogotá. She asked the participant (Mario) to tell his life experiences in relation to his school and his role as student. In the narratives, Mario reflected about his life and decision making and so, Guerrero pointed out that "as narrators, we evaluate events of our lives in terms of the cultural norms and expectations of our particular community. In this way we affiliate with other members of society" (p. 90). Narratives imply reflection and, consequently, identification with the people around the narrator. Mario declared himself to feel out of place because he was older than his classmates. He had quit different schools several times and he perceived himself more as a rocker musician than as a student. In that sense narratives displayed very deep insights that were exteriorized by means of writing.

Narratives can also be helpful to analyze not only students' insights, but also teachers' insights. Golombek and Johnson (2004) proposed a research study in which they examined the emotional and cognitive conflict in teachers by means of narratives. These authors asserted that narratives allow people to interpret and re-interpret the world and their lives; that means that narratives involve a reconstructive process. The previous argument allowed Golombek and Johnson to state that narratives are a useful instrument to understand teaching from the point of view of a teacher. The previous ideas propose that narratives are the most appropriate strategy to exteriorize teachers' thoughts. Besides, teachers are constantly making sense of who they and the others are because narratives involve a reconstructive process. 
Narratives as a reflective exercise make people analyze and make sense of their lives and roles in a society. The main issue to study in narratives is people's experiences and how they create meaning from those experiences. "In the experience-centered approach, narratives are the means of human sense-making: human beings create meaning from their experiences both individually and socially" (Bruneret et al. as cited in Miyahara, 2010, p. 6). Narratives are separate pieces of experiences. They reveal the insights of a person in relation to an issue that was lived in a specific moment in her/his life. Those pieces of writing, when connected, provide a full narration that can be understood as a unit. Writing narratives is not just writing about oneself, but also, how people provide meaning to the events narrated.

The narratives implemented in this intervention were divided into five sessions. In each session, students wrote about specific topics and elaborated a sequence that allowed the researcher to analyze the narrations both as fragments and as a whole unit. Each fragment contained students' reflections and life experiences. These narratives are not one single text, but many small fragments that compose a larger unit. The following chapter provides detailed information about the way narratives were implemented.

\section{Description of the Experience}

As said before, the context in which this intervention was carried out is a public university in Tunja (Colombia). This university has two languages programs and their common goal is to train future language teachers. Each one of these programs has in their syllabi subjects related to specific areas of knowledge: pedagogy, didactics, research, foreign language teaching and learning, reading, writing, phonetics, and many more.

The subject in which the narratives were implemented was addressed towards exercising students' reading and writing skills. The thematic content of the subject was divided into two sections. The first half of the semester students read several kinds of texts in order to work on their reading skill. They read stories, poetry, science fiction, academic essays, newspapers, and watched movies. All the previous sets of materials were studied with the purpose of having students reflect, understand, and judge the content expressed in the audiovisual material. Students exercised their writing skill in the second half of the course. Students were asked to review the information about paragraph structure and punctuation; by means of their own texts, grammar, semantics, and vocabulary were revised. It could be asserted that narratives allowed the teachers to personalize learning. Each student from his/her texts identified the aspects in which they felt weak or confused about: conjugation, sentence construction, semantics, descriptions, and so on.

Two main issues were considered for this intervention, one of them was to encourage students to write. Second, students were asked to analyzed how the formal aspects of language can be applied in their texts. The written exercises proposed by the program of the 
subject involved writing essays or reviews. In that sense the program was modified and narratives were included in addition to the academic writing exercises. This means that students kept writing the type of texts that the program required and also, they were able to explore their own lives through the creation of narratives.

In an informal talk, students argued that writing was not easy. They also stated that writing in English was hard because they must know grammatical rules, for instance, how to use punctuation as well as using the most appropriate words to imply the meaning they want. From experience, it has been perceived that students are right. Their texts are hard to comprehend. They make up words and their grammar is not accurate enough. Besides, from the teacher's perspective, it has been perceived that when students are asked to write essays, their texts lack APA parameters and some of them do not know how to quote authors.

Students seemed to be reluctant to write academic papers. For them, APA parameters are confusing. Also, looking for authors is demanding and comprehending theory is not easy. In that sense, the writing exercises were altered and, after introducing narratives, students were eager to write and ask questions of the teacher in relation to expressions and vocabulary. While in the case of the essays students were more concerned about their grades, with the narratives they wanted to find the most suitable descriptions for the images they wanted to create. From the pedagogical perspective, students felt more comfortable writing their narratives than academic texts and, as a consequence, some of them expressed their willingness to keep writing on their own and to keep collecting memories in their notebooks.

Before implementing the narratives it was necessary to analyze some aspects. At first, the concern was how to implement the narratives, which meant that students would be asked to write five chapters but it was necessary to focus the texts on a specific topic. Bearing in mind that narratives are based on personal experiences, students were asked to write about specific aspects of their lives. The topics proposed were: my childhood, the place I like to be, the things that I like and that I bate, my life at the university and what I want for my future. The topics were chosen because it was perceived that students struggled to start writing when they did not have a theme to focus on. They wrote their narratives, but they mixed many situations or aspects of their lives that confused the reader about the content.

Nevertheless, the five topics proposed were not necessarily the ones that students had to write about. They were told that if they had any problem to start writing they could develop their chapters based on a specific topic. Some students followed the proposed prompt, but others decided to write about what they preferred. This freedom motivated the writing process. Also, it is worth mentioning that students were not judged by the content of their narratives. In that sense, the narrators felt free to express their voices with the words they wanted and to tell the story of their lives. 
Another interesting aspect was that for students it was not easy beginning to write. They had many problems starting their narratives because some students mentioned that there were many things to tell, and others stated that their lives were not interesting enough to be written about. Despite the initial obstacles, each student achieved writing the drafts of their first narratives in class and later came to tutorials to revise what they had written on their own. As the writing sessions went on, students were able to write and analyze their own narratives and themselves to suggest some changes. Eventually, each student printed their lives on a piece of paper the way they wanted to.

The process of writing narratives required students to work hard. They seemed to challenge themselves in relation to the descriptions and word choices. Also, they wanted to create stories, build plots, and provide the reader with images to exemplify students' life situations. For example, a student mentioned that she loved to be alone, in her bedroom, drinking a glass of wine, and reading poetry. Another student stated that she graduated as an agricultural engineer because her father wanted to have three female engineers in his house, but that she did not find any usefulness in that career. Also, there was another narrative that illustrated what the writer felt when her mother died, how she had to face life and how her days changed ever since. In another narrative, a student described how important theater was for him. He mentioned that he enjoyed being on stage and the hidden love he felt for the main actress of the play. There are many narratives that exemplify the way a language student lives his/her life. There are many feelings immersed in those texts and there are many sensations that are impossible to ignore. Everything spun around the target language and more importantly, around students' voices.

The narratives were implemented over ten weeks. The idea for the intervention was to write during one session (two hours) on one of the topics proposed. While students were writing, the teacher checked their texts, and recommended some verbs, words, or descriptions to enrich students' production. The students proposed the content and the teacher helped them to achieve the descriptions they wanted to illustrate. Among the formal aspects that were taken into account were to state a situation, to develop descriptions around that situation, and to propose a reflection around the addressed topic. Additionally, students were required to revise their punctuation, their grammar structures, to write shorter sentences and to develop one idea per paragraph. After implementing the writing exercise, it was perceived that, on the one hand, students wrote many pages, and on the other, they were willing to write and do so more meaningfully so that their writing skill improved.

As noted above, for the purpose of this pedagogical intervention the main requirement for students was to write. It did not matter what the topic was, they had the choice to follow the teacher's prompt or to write about something else. Nevertheless, after collecting all narratives, it was established that students involuntarily applied a textual structure in their 
narratives. Unconsciously, students followed some of the aspects mentioned by Labov and Waletzky (1967). The teacher did not propose a predefined structure neither did he ask students to follow a specific parameter for writing. Surprisingly, despite all narratives being different, students implicitly followed or looked for a way to tell their stories by applying their own structure, which in most cases matched the taxonomy mentioned above.

\section{Findings}

The participants of the present intervention did not exhibit all the six elements proposed by Labov and Waletzky (1967). Nevertheless, they did present in their narratives the orientation, the complicating action, and the evaluation. The orientation was evident because students situated their texts in temporal or spatial contexts. In the complicating action, the participants narrated their events, for example, the moments they lived in specific times, the people that were influential in their lives, or the problems they had faced. In the evaluation, students reflected upon what they lived; they also analyzed and explained in their narratives the way they felt in certain situations and why. They also narrated their perceptions about their future, to wit: "Although not all narratives necessarily include all of these six elements, at a minimum a narrative must include the complicating action, a temporal component, while it is the evaluation for establishing the point or the meaning of the story" (Labov and Waletzky as cited in Elliott, 2005, p. 8). Consequently, in the present intervention, narratives were structured texts that allowed reflection and self-evaluation of life experiences.

Narratives also proved to be an appropriate strategy to encourage language students' to write better. They practiced their grammar and by means of the exercises, they were able to realize all the information that was needed by a reader to comprehend a text. Besides, the connection of English and their own life permitted the participants to express what they wanted. The narratives motivated students to write, not only for the course, but also because they wanted to create satisfactory texts. Eventually, students became aware of punctuation, paragraph structure, and grammar in order for them to be understood by readers.

From my experience as a teacher, students generally write texts that are not connected to them. It seems that they write only because they will get a grade in return for their work. They do not write because they would like to show the way they think. Therefore, narratives were essential in order for students to write meaningful texts, to illustrate personal events and to show their reflections about what happens to them daily.

\section{Narrative Content and Discussion}

Among the pieces collected, students revealed their insights about their lives. Every person lives and perceives life differently. Although the texts are not grammatically or 
syntactically accurate, the semantics of each one of them demonstrates reflection, arguments, and students' voices. It is worth mentioning that students took between seven to eight weeks to write their narratives. They invested a lot of effort and every student wanted to have the most expressive text.

There are some feelings related to students' lives. They feel fine being in a specific place; they can feel that they know themselves, that life has been hard or that there are differences between men and women. The following narrative samples relate to students' sensations towards certain aspects in their lives.

The place I love to be is my bedroom. That's the perfect place for me in my bedroom there is a world full of ideas and feelings...in my bedroom I use to play songs and to procrastinate. I can spend my weekend in my bedroom and I like it...in my bedroom I am used to do my concert rehearsals and my best public ever is: my bed, the closet and the night table. It is amazing for me [sic]. (Student C)

Every person likes to be in a certain place. The previous narrative reveals what a bedroom can be for; in this case, a bed is a place to dream and to evoke the most intimate feelings. It could be stated that for this student, his bedroom is his secret, his desire, and his illusion. In the next narrative, there is a word that summarizes its content: identity. The following excerpt exemplifies how the student sees herself and the projection of the identity that she wants to display before others.

My house is the place where I love to be, because it is warm, I can be quiet in my room, sharing joys and sorrows with people who I live. However, it is somewhat ironic because I felt fear, pain, anguish, nostalgia, anger by things dad my dad has made us. But still there is not place that can be compared like sitting here in my bed, recalling those bad times, with a bit of cold, thanking God for his company and the opportunity of having a comfortable ceiling that perhaps, few or many people do not have. Among the things I like to do is spooling my cat that seems a stuffed animal and whitey, I like watching TV or movies, read newspapers, magazines or soup operas. I like making me masks, doing my nails, I love inventing drawings or cartoons. I like making that my remaining works, are differently and creatively with the knowledge that I have to decorate. I love being with my boyfriend to remember such authentic, unique and special moments, tell him how much I love him and how important is for my life and for me [sic]. (Student E)

The previous narrative has many characteristics that are worth analyzing. This text illustrates a complication that comes from what a student is living. There is a house that despite causing one to recall sad moments, it is like a shelter. This student reflects upon the fact of having a house and of living a hard past that is over. Also, the narrative mentions a person that is important for the writer, a person that seems to be a support in hard times. In that sense, this narrative in particular contains a deep reflection as to how life is around a house and what it represents.

As can been seen, none of the narratives are perfect in terms of grammar. Despite there being many corrections needed, at the end the narratives kept some inconsistencies in terms 
of punctuation and grammar. It is important to clarify that despite the existence of some mistakes, the message can be completely understood by the reader. At this point it can be mentioned that the students themselves made the decision about when to stop writing and when to stop revising and editing. They were aware that a text is never finished and that corrections can become a never ending process. In that sense, all the samples selected are what students considered to be their final product.

I often feel out of place in classroom. I feel a little old. But it does not matter. Time is running so fast and the most important thing is that I am studying for myself. I graduated as Agricultural Engineer because I did not think in a future doing something that I did not like or perhaps, I studied Agronomy because I did not want to stay behind of my three older Agronomist sisters. I think that I found in Languages the opportunity to grow intellectually, rather than stay at home feeling sorry for having studied something I was not interested [sic]. (Student C)

This last narrative is special because of the writer and what she implies. In class, this student was very quiet. She was always worried about her assignments and did not seem to have many friends. After reading her narratives, the reason why she was so shy could be perceived. Her decision to study languages allowed her to listen to her own voice. Also, it seems that languages gave her the opportunities to learn what she could not in the formal sciences. This narrative implies that despite teachers and students sharing a classroom and some knowledge, writing allows a teacher to know who his/her students are. This is the relation that some students ask to have with their teachers, that is, sometimes apprentices need someone who listens. Sometimes they need a "human being" instead of perfect teachers that know all the theory about languages.

Since narratives are recollections of memories, there are many that students want to tell. Most of the students mentioned issues in relation to their childhood or about situations they lived/experienced in specific moments. Memories in particular reveal the existence of the writers, their lives and who they are according to their own eyes.

Narratives can be a meeting point between what a course requires and what students would like to do. The result from combining a writing course and the narratives is that students exercised their writing skill from an internal perspective and as the sessions went by, they demonstrated their apprehension in relation to what writing implies: the plot, the grammar, the ideas to be developed, and so on. Other positive results that can be deduced are that students felt eager to write, to work on their narratives and they sought to feel satisfied with their texts. Finally, students were given a space for them to exhibit their own voices, to write about them and to reflect upon their actions.

This story starts with a young girl, who was born in a difficult situation. She was born in a conflictive family, in those times they did not have money, they did not have work, and all the money that they got was for the savings. She has 2 brothers, but they did not love her. And her mother and fatherwere not so understanding. All the mistakes that she made were punished, in a several way, "I do not have 
the skin with that I was born", she told me once. Her parents were cruel, and bad with her. Maybe they did not wish a girl like their son, I do not know. Since that she has memory she had have to work, everyday, for her food, her parents told her, "If you do not work, you do not eat," and her brothers told her that too. Yet, the story gets better. Her parents do not let her study, although she had a lot of wishes to learn. In those times, when only men could learn, a girl with those thoughts could not do anything. But although of all these problems she was learning every day, of course she was not learning how to read, to write, to speak, but she was learning the most important lesson for her life. Nothing in life is easy, if you want something, fight for it, do not let that people destroy your dreams. This lesson did not help her to study or to get money, but this lesson was helpful for all her life. In those times Natalia found the love [sic]. (Student N)

This sample has a special writing style. This student chose to narrate her life in third person, which implies that it would be as if she were watching a life, as a camera filming a movie. This is the way a student started her narratives, she started telling her mother's story, how she had to struggle, to find herself a place and to try to survive. For the writer of this narrative her mother was her hero, she admires her and that is why the text begins quoting painful moments in her life. Despite pain, at the end of the paragraph there is a nice word: love. This love was her daughter.

Supposedly, teachers have the knowledge in the classroom, but it does not mean that students do not know anything. With the narratives, as the previous one, students proved to be reflective, to have life experiences that have molded them as they are. The situations that apprentices live can be visible only by means of writing. There are so many narratives, so many feelings and points of view that after reading them it is impossible not to feel some kind of affiliation towards their writers. Students are inside a classroom, but just a few teachers ask themselves who students are, or just a few even care about their students' names. Sometimes students can teach more than what their teachers imagine.

The previous samples exemplify when a narrative becomes more important than the formal aspects of writing. This is when some lines become pictures as in a movie. Students' narratives are themselves, their voices, and their ways of seeing their worlds. A narration is a space that some students need. Sometimes they need to say what they want as they want it. A piece of paper and some freedom can help students to overcome daily problems and also, to practice the target language.

At the end of each term students were asked to write a paper in which they narrated their writing process. Despite the narratives having contained sensitive issues, students did not mind writing about them. Apprentices argued that they wanted and needed to write their painful experiences and that, according to them, having those memories and feelings written made them feel better. In their final paper, students mentioned their process, how they felt writing, and their expectations as writers. The following sample was written by one of the students. 
The process of writing my life on pieces of paper was so interesting. I found reminds about my mother, my father, my family and friends that I thought lost. The process was hard, not for the fact of writing; more for the fact of finding the right words for expressing what I want to say. I think that English is more formal than Spanish, and less poetic, or maybe I should increase my vocabulary for founding the suitable words. In the process was interesting how I could increase my vocabulary, to learn the tenses of some verbs, to create a new world full of reminds in my mind, reminds that in the paper do not going to disappear. When I began this semester, I believed that the most important skill in English was speaking and writing was not so important. Now I think, that if you cannot write in a communicative way, you do not going to speak in a communicative way. I think that the most important thing, of this kind of exercises, is that we can express our feelings, who we are, without the afraid of being criticize for our mistakes. To write about us is a good way of starting our path like writers, if you can express who you are; you can express everything that you want. Also, I think that every of us could became great writers, if we write about topics that we love, interesting topics for us, thinks that for some reason left a footprint in our mind or heart; the process of writing does not going to be difficult, boring, and we going to write for the enjoyment of writing, and no for get a good great in our tests or semester. The process of writing, going to be an adventure more. I hope that in the future I could express my ideas in a clear way. I hope that my path like writer has started since right now [sic]. (Student $\mathrm{N}$ )

The previous sample has an implication: to be a writer. From the pedagogical perspective, it is interesting to analyze how students build their texts and how they feel that the path to becoming a writer is by starting. An aspect that is worth highlighting has to do with the fact of criticizing what students write. As seen in the previous sample the narrative exercise encouraged students to write. They felt more committed to achieving a good narration rather than getting a high score. As a teacher, I can say that students' voices are worth being heard. A way to hear them and to improve students' writing is by means of narratives. A teacher's job can be fulfilled in many ways, but it is more rejoicing when a job becomes the pleasure of knowing people, the pleasure of seeing the humans beings that are in a classroom, a teacher's job can be more pleasant when teachers give themselves the chance to touch the life of his/her students. That coexistence can be possible by means of writing.

\section{Conclusions and Pedagogical Implications}

The inclusion of narratives was relevant to motivate students to write. Students realized that apart from structure and correct words, their narratives needed to communicate the narrator's impressions. By means of narratives, students enriched their vocabulary and more importantly, they worked on their texts giving the reader a meaning. Narratives allowed students to explore their writing abilities based on their own feelings.

From experience, I can assert that each semester I have had talented writers. Many narratives have been read and many lives have been illustrated. A classroom holds plenty of 
sensations that can be used as material for learning a language. Writing reveals students' uniqueness and that is why writing is so interesting. Students have many things to say, the teacher can provide those spaces for students to speak, writers can be found anywhere, the premise is to let students just write!

There are two aspects that are worth mentioning in relation to the inclusion of narratives as a writing strategy. For students, it was easy to write their narratives. Nevertheless, some of the problems they mentioned had to do with vocabulary and grammar. Despite narratives being based on personal facts, these students paid a lot of attention to grammar and vocabulary when writing. After reading their narratives and providing suggestions, apprentices realized that, despite the importance of grammar, intentions, descriptions, and illustrations are also part of a text.

Another comment has to do with the role of the teacher. Teachers are important in the process of writing narratives. Due to the intimacy of texts, the teacher must be supportive and sensitive to the situations that students express. Students trust in their teachers when sharing their papers, consequently, their contents must be read respectfully and responsibly. The point of implementing narratives is to be able to understand and to know students. Sometimes apprentices need an opportunity to show who they are and how they feel. Sometimes students need someone who understands them.

\section{References}

Castañeda-Peña, H. (2008). 'I said it!'I'm first!': Gender and language-learner identities. Colombian Applied Linguistics Journal, 10, 112-125.

Elliott, J. (2005). Using narrative in social research: Qualitative and quantitative approaches. London, UK: Sage.

Golombek, P. R., \& Johnson, K. E. (2004). Narrative inquiry as a mediational space: Examining emotional and cognitive dissonance in second-language teachers' development. Teachers and Teaching, 10(3), 307-327.

Guerrero, A. L. (2011). Narrative as resource for the display of self and identity: The narrative construction of an oppositional identity. Colombian Applied Linguistics Journal, 13(2), 88-99.

Kim, Y., \& Kim, J. (2005). Teaching Korean university writing class: Balancing the process and the genre approach. The Asian EFL Journal, 7(2), 69-90.

Labov, W., \& Waletzky, J. (1967). Narrative analysis: Oral versions of personal experience. In J. Helm (Ed.), Essays on the verbal and visual arts: Proceedings of the 1966 Annual Spring Meeting of the American Ethnological Society (pp. 12-44). Seattle, WA: University of Washington Press.

Miyahara, M. (2010). Researching identity and language learning: Taking a narrative approach. Language Research Bulletin, 25, 1-15.

Pavlenko, A. (2008). Narrative analysis. In L. Wei \& M. G. Moyer (Eds.), The Blackewell guide to research methods in bilingualism and multilingualism (pp. 311-325). Malden, MA: Blackwell Publishing. 
Riessman, C. K. (2003). Analysis of personal narratives. In J. A. Holstein \& J. F. Gubrium (Eds.), Inside interviewing: New lenses, new concerns (pp. 331-346). Thousand Oaks, CA: Sage.

Rivas Rivas, L. (2013). Returnees' identity construction at a BA TESOL program in Mexico. PROFILE Issues in Teachers' Professional Development, 15(2), 185-197.

Rodriguez Guanume, G. A. (2013). Adolescents' narratives: An exploration of themselves from a social literacy practice (Master's thesis). Universidad Pedagógica y Tecnológica de Colombia, Tunja.

\section{The Author}

Fredy Orlando Salamanca González has taught at Universidad Pedagógica y Tecnológica de Colombia in the BA in languages program since 2010. He holds an MA in language teaching and has published papers in academic journals in Colombia and has presented in academic events. 